\title{
In admiration of Rainer Nagel
}

\section{Jerome A. Goldstein}

Received: 20 February 2012 / Published online: 15 March 2012

(C) Springer Science+Business Media, LLC 2012

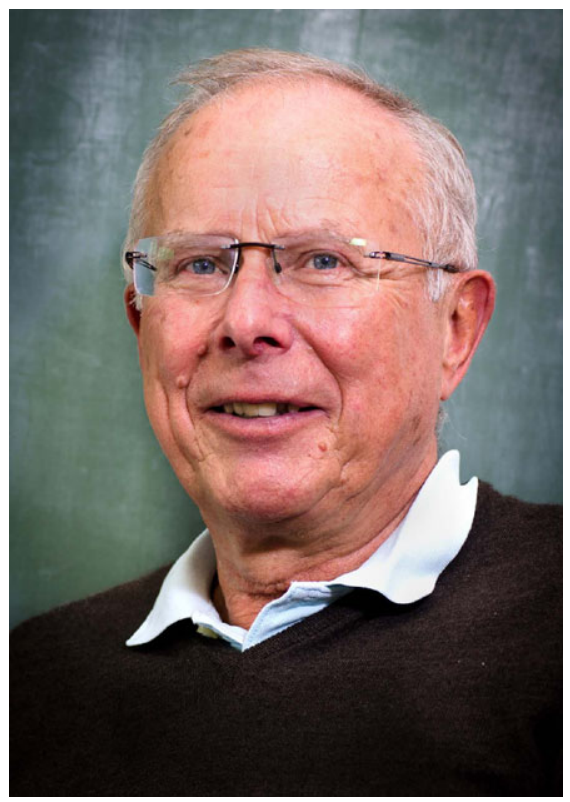

Rainer Nagel is an outstanding research mathematician, teacher, mentor, organizer and friend. And he weaves these things together so seamlessly that it is difficult to discuss one of his attributes without bringing in the others.

Communicated by László Márki.

J.A. Goldstein $(\bowtie)$

Department of Mathematical Sciences, University of Memphis, Memphis, TN 38152, USA

e-mail: jgoldste@memphis.edu 
His academic life has been spent primarily at the University of Tübingen, where he was first a student and then a professor. His doctoral thesis advisor was Helmut Schaefer, under whose influence Rainer quickly became an expert in the functional analysis associated with positive linear operators on ordered Banach spaces. These operators arise naturally in problems of applied mathematics and differential equations where the solution is interpreted as a density or concentration or mass or something else which is a nonnegative function. The natural domain for these applications is the context of operator semigroups, and the theory of positive (or positivity preserving) semigroups in the early 1970s contained a major theorem of Ralph Phillips and little else. Rainer decided to create a complete theory of positive semigroups on ordered Banach spaces. This was an enormously broad and ambitious program that no individual could possibly do alone. So Rainer built up a large research group to do this in a teamwork context. This group became known as AGFA (Arbeitsgemeinschaft Funktionalanalysis), and its main focus was positive operator semigroups and applications.

I first met Rainer in person in June 1981 in Tübingen, although we had gotten to know each other well through correspondence by then. I was stunned and amazed by the "high tea" in his office in the late afternoon on the day we first met. There were, as I still vividly recall, about twenty AGFA people there, including graduate students, postdoctoral fellows, faculty members and visitors. It was a banquet of high level discussions, conjectures, and ambitious plans and hopes. It was like a symphony orchestra with Rainer as conductor. The young researchers included the budding stars Wolfgang Arendt and Günther Greiner. And there were lots of excellent mature scholars such as Ulf Schlotterbeck. The mathematical level and the levels of cooperation, friendliness, informality and sharing ideas were amazing. I had never seen anything like it before, but although the names of the AGFA crowd regularly changes, the spirit of AGFA remains the same as does the brilliance and work ethic of its leader.

Rainer was and remains a marvelous doctoral thesis advisor. Unlike many, I would say most thesis advisors, Rainer gives his best problems to his students, rather than saving them for himself. I suspect he has previously partially solved some of these problems prior to assigning them, but Rainer will not admit this. His deservedly great reputation as an advisor spread and he attracted students from all over the world. He is one of a select group of mathematicians who has advised over fifty doctoral theses. According to the Genealogy project he has had 56 successful doctoral students, plus there are 6 current students plus many more who were largely advised by Rainer but officially by someone else. Among the many current distinguished researchers coming from AGFA are Arendt and Greiner (who became a world class computer scientist) and, in alphabetical order, Simon Brendle, Tanja Eisner, Klaus-Jochen Engel, Matthias Hieber, Frank Neubrander, Abdelaziz Rhandi, Roland Schnaubelt, and many others. He has had long term scientific relations and collaborations with Silvia Romanelli (Bari), Eugenio Sinestrari (Rome), and many others. His great organizational skills and his legendary lectures resulted in seemingly uncountably many invitations to give conference lectures and short courses all over the world. He is the founder of the ongoing Internet Seminar, which is an annual course on semigroups, evolution equations, et al. for young researchers worldwide. At the end of the course in June, the participants meet in a great conference in Blaubeuren, an excellent 
Oberwolfach-like conference center. Rainer also runs seminars involving sports and mathematics (in awesome locations), an annual Rome Seminar on mathematics and philosophy, and other things such as the unique, legendary conference at Castel del Monte near Bari, combining history, architecture and geometry. Rainer has also been a successful advocate for student exchange and mobility programs involving Europe, Africa, North America and the Far East.

$\mathrm{He}$ is (jointly) responsible for two major books, both milestones in the history of positive semigroup theory. The first is a Springer Lecture Note volume [1] published in 1986 with 9 authors. Rainer decided that AGFA (including some then current members and some alumni) should write a definitive selfcontained monograph on positive semigroups. He collected his collaborators, rented rooms at a conference center, and got the nine of them to revise, tie together, and unify the separate chapters written in advance by various subsets of the authors. It is amazing that this book has a smooth and consistent style, as well as a lot of new and recent research organized into one volume for the first time. It is as if he locked his "orchestra" into a room and led the composition of their symphony into a masterpiece before allowing them to leave the room. The result was wonderful, and only Rainer could have coordinated this in this way and in a very timely fashion. The application areas included Perron-Frobenius theory (a la AGFA), ergodic theory, age dependent population dynamics, mathematical biology, et al.

The second book, a hard cover Springer book written jointly with K.-J. Engel, [2], is currently the best source for beginners (as a masterful text) and experts as well. It is filled with new results, new perspectives, new motivation, new applications; it has very broad scope. A shortened and updated version [3] of this book was published in 2006.

Rainer remains a remarkable athlete, and he always liked to combine mathematics with athletics and group social activities. At his home in Horb, Rainer and his wife Ursula regularly hosted AGFA social activities. For many years, there was an annual AGFA miniconference at Tuebingen, followed by a $40 \mathrm{~km}$ bicycle race to Horb, and then a big party. Rainer won all these races except for one, when a young lady from AGFA was the best cyclist (showing again that one must always consider the possibility of counterexamples). Rainer still takes "character building" long bicycle rides in the mountains with friends who are former Tour de France competitors. In addition to his expert cycling, Rainer has long been an excellent runner and swimmer. He has run marathons and competed in many triathlons. An additional time consuming source of joy for him is playing with his five grandchildren, all born within the last five years. But he no longer does marathons and triathlons, although it would not surprise me if he decided to make a comeback at age 75 .

Rainer was cofounder of the Journal of Evolution Equations (with Wolfgang Arendt) and an important and effective editor of Semigroup Forum and many other journals as well. He continues his active research program in spectral theory, positive semigroups, delay and functional differential equations, flows in networks (which ties graph theory to positive semigroup theory), operator matrix theory with applications to partial differential equations, and other topics. When I give a lecture and refer to a result as Nagel's theorem, Rainer always corrects me and says which of his collaborators deserves much of the credit. This is not merely a reflection of Rainer's modesty. Rather it indicates his love for his students and collaborators and his generosity. 
Rainer officially retired in the fall of 2008. His retirement conference attracted several hundred attendees. Rainer, being Rainer, insisted that it be called AGFA 35, and that it was in honor of the 35th anniversary of AGFA. It was a remarkable event. It is hard to imagine the show of affection and admiration that so many people had for Rainer. But even though Rainer is officially retired, a visitor to Tübingen would never guess that. AGFA remains alive and vibrant, with remarkable high teas in Rainer's office. He, his current doctoral students, faculty and visitors have exciting discussions with Rainer still providing the leadership. Rainer's passion for thinking deeply and constantly about hard problems and new research directions continues with no indications of slowing down. I never met anyone else who is loved and respected so much both personally and scientifically by so many colleagues as Rainer. AGFA 35 proved this, and Rainer's current activities continue to justify it.

I am most fortunate to have Rainer as my good friend and mentor. I marvel at how he so gracefully maintains his charm, his athleticism, his brilliance and creativity, and his generosity. He remains the favorite role model for many, myself included.

\section{References}

1. Arendt, W., Grabosch, A., Greiner, G., Groh, U., Lotz, H.P., Moustakas, U., Nagel, R., Neubrander, F., Schlotterbeck, U.: One-Parameter Semigroups of Positive Operators. Lecture Notes in Mathematics, vol. 1184. Springer, Berlin (1986)

2. Engel, K.-J., Nagel, R.: One-Parameter Semigroups for Linear Evolution Equations. Graduate Texts in Mathematics, vol. 194. Springer, New York (2000) (with contributions by S. Brendle, M. Campiti, T. Hahn, G. Metafune, G. Nickel, D. Pallara, C. Perazzoli, A. Rhandi, S. Romanelli, and R. Schnaubelt)

3. Engel, K.-J., Nagel, R.: A Short Course in Operator Semigroups. Springer, New York (2006) 